\title{
Dietary Cholesterol-Induced Hyperlipidemia Modulates Lipid Synthesis in Rabbit Monocytes*
}

\author{
Seema Gupta, ${ }^{1,2}$ Alan B.R. Thomson, ${ }^{2}$ Tessa Kappagoda, ${ }^{3}$ \\ and Manohar L. GARG ${ }^{1,2, * *}$ \\ ${ }^{1}$ Department of Foods and Nutrition, and ${ }^{2}$ Division of Gastroenterology, \\ University of Alberta, Edmonton, Alberta, Canada \\ ${ }^{3}$ Division of Cardiovascular Medicine, University of California, \\ Davis, California, U.S.A.
}

(Received November 17, 1992)

\begin{abstract}
Summary Lipid synthesis in monocytes isolated from rabbits fed a high-cholesterol diet and subsequently a low-cholesterol one was examined. Rabbits were fed diet containing $2.5 \%(\mathrm{w} / \mathrm{w})$ cholesterol for 3 weeks and then transferred to a normal diet for another 6 weeks. The total and free cholesterol levels in the blood increased up to 3 weeks and then steadily decreased. Esterified cholesterol increased only during the first week on the high-cholesterol diet and then decreased throughout the remainder of the experimental period. Lipid synthesis, as assessed by [1${ }^{14} \mathrm{C}$ ] acetate incorporation, was significantly reduced in monocytes isolated from animals on the high-cholesterol diet. This reduction in lipid synthetic activity continued another 3 weeks even after cessation of the high-cholesterol diet and then lipid synthesis was rather increased significantly. Specifically an increase in cholesterol and fatty acid synthesis was observed when animals were fed a high-cholesterol diet for 3 weeks and then allowed to recover for another 6 weeks.
\end{abstract}

Key Words: dietary cholesterol, hyperlipidemia, lipid synthesis, monocytes (rabbit), cholesterol metabolism

Accumulation of cholesteryl ester-rich lipid droplets in the arterial intima is characteristic of the presence of fatty streaks or atherosclerotic plaque. Recent studies have demonstrated that dietary cholesterol-induced hypercholesterolemia

* Presented in part at the annual meeting of the Canadian Federation of Biological Sciences in Victoria, B.C., Canada.

${ }^{* *}$ To whom correspondence should be addressed. Present address: Department of Nutrition and Dietetics, 3rd Floor, Medical Sciences Building, University of Newcastle, Newcastle, NSW 2308, Australia. 
in rabbits is associated with an increase in cholesterol content of the aortic tissue [1-3]. The reversal of hypercholesterolemia by switching the animals to a normal diet, however, failed to bring the aortic cholesterol level back to normal. Rather, the aortic levels of cholesterol were further elevated after the animals were shifted to a normal diet [1-3]. These studies suggest that initial cholesterol feeding may cause an irreversible deregulation of the cholesterol metabolism in the arterial wall, which may be an important event in the development of atherosclerosis. The mechanism(s) by which dietary cholesterol damages aortic cholesterol homeostasis are far from clear.

Monocyte-macrophage infiltration of arterial tissue is one of the earliest detectable events in the atherogenic process [4-6]. The lipid-filled foam cells present in the arterial walls are considered to be derived from the monocyte/ macrophage [5, 7-9]. The circulating monocyte and macrophages are capable of actively synthesizing cholesterol and metabolizing lipids $[10,11]$. The arterial lipid accumulates as a result of metabolic changes taking place within these cells. Studies from several laboratories using a variety of techniques strongly implicate the monocyte/macrophage as a cell of importance in the atherosclerotic lesion [12]. In an attempt to define the mechanism for diet cholesterol-induced damage to the aortic cholesterol metabolism, we examined lipid synthesis in freshly isolated monocytes from rabbits, as this is the cellular entity that invades the vessel wall. The effect of cholesterol feeding and subsequent reversal of diet-induced hypercholesterolemia on lipid synthesis by monocytes was examined.

\section{MATERIALS AND METHODS}

Materials. $\left[1-{ }^{14} \mathrm{C}\right]$ Sodium acetate (specific activity, $2.0 \mathrm{mCi} / \mathrm{mmol}$ ) was purchased from New England Nuclear, Boston, MA. Heparin $(1,000 \mathrm{U} / \mathrm{ml})$ was obtained from ICN Biochemicals, Cleveland, OH. Ficoll Hypaque, Eagle's EDTA, MEM, and other biochemicals were purchased from Sigma Chemical Company, St. Louis, MO. TLC plates were purchased from Analtech, Inc.

Animals and diets. Male New Zealand white rabbits (1.6-1.8 kg) were randomized into 2 groups so that their average body weight per group was similar. One group $(n=8)$ was fed a standard rabbit diet for 9 weeks, and the other group $(n=8)$ was fed the same diet supplemented with $2.5 \%(\mathrm{w} / \mathrm{w})$ cholesterol for 3 weeks and then switched to the standard rabbit diet for a further 6 weeks. Food and water were available to the animals at all times. Body weight of the animals and food intake were monitored on a weekly basis. A small amount of blood was taken from the animals for serum cholesterol analysis $[13,14]$ every week, while 20-25 ml blood was withdrawn at 3,6, and 9 weeks of the dietary regimens for monocyte lipid synthetic studies as explained below.

Isolation and purification of monocytes. Blood was obtained by venepuncture, with $0.5 \mathrm{ml}$ of heparin used per $20 \mathrm{ml}$ of whole blood. Monocytes were isolated by the method of Edelson and Cohn [15]. Ten milliliters of blood was 
layered over $16 \mathrm{ml}$ of Ficoll-Hypaque mixture and centrifuged at room temperature at $400 \times g$ for $40 \mathrm{~min}$. The mononuclear cells were recovered from the band at the plasma Ficoll-Hypaque interface. These cells were diluted in $30 \mathrm{ml}$ of Eagle's EDTA and centrifuged at $200 \times g$ for $10 \mathrm{~min}$. The supernatant was discarded and cells were resuspended in minimum essential medium (MEM) containing 10\% heat-inactivated autologous serum. Cells in $1.5 \mathrm{ml}$ of the medium were dispensed into each of several $30-\mathrm{mm}$ Petri dishes at a concentration of $2 \times 10^{6} \mathrm{cells} / \mathrm{ml}$. The dishes were then incubated in a humidified $5 \% \mathrm{CO}_{2}$ incubator for $2 \mathrm{~h}$ to allow the monocytes to settle and adhere to the substratum.

Lipid synthetic studies. Lipid synthesis in normal and dietary cholesterolinduced hypercholesterolemic rabbit monocytes was examined with $\left[1-{ }^{14} \mathrm{C}\right]$ acetate used as a substrate. After $2 \mathrm{~h}$ of incubation in a humidified incubator, the medium was aspirated, and the dishes were then rinsed three times with culture medium without serum to dislodge contaminating non-adherent cells. The Petri dishes were refilled with $1.5 \mathrm{ml}$ of culture medium containing $1 \%$ autologous serum and [1${ }^{14} \mathrm{C}$ ] acetate (specific activity, $2.00 \mathrm{mCi} / \mathrm{mmol}$ ) and incubated in a humidified $5 \%$ $\mathrm{CO}_{2}$ incubator at $37^{\circ} \mathrm{C}$ for another $2 \mathrm{~h}$.

The medium was withdrawn with a Pasteur pipette and stored in screwcapped tubes for lipid extraction. The cells were scraped off with the help of a rubber policeman and stored in screw-capped tubes in phosphate buffer for further analysis. Lipids were extracted by the method of Folch et al. [16] and fractionated by thin-layer chromatography using a solvent system containing hexane: diethylether: acetic acid $(85: 15: 1)$. The spots corresponding to phospholipids, free fatty acids, triacylglycerols, and cholesteryl esters fractions were scraped off and counted in a liquid scintillation counter (Beckman Model, LS 5801). Protein was estimated by the method of Lowry et al. [17].

Statistics. The data has been presented as the mean \pm standard deviation. Paired Student's $t$-test was used to determine the effect of feeding the animals, a cholesterol-supplemented diet and subsequently a normal diet.

\section{RESULTS}

The average body weight gain of the rabbits after 9 weeks on dietary regimens was similar $(2.2 \mathrm{~kg})$ in both the control and the cholesterol-supplemented groups. Both groups of animals consumed a similar amount of food.

\section{Cholesterol content}

Dietary cholesterol supplementation brought about a massive hypercholesterolemia in rabbits, reaching a maximum of $2,191 \mathrm{mg} / \mathrm{dl}$ at the end of the 3-week period (Fig. 1). When the animals were shifted back to the normal, low-cholesterol diet, the plasma cholesterol level gradually decreased to $312 \mathrm{mg} / \mathrm{dl}$ by 9 weeks. The increase in unesterified cholesterol content followed the same pattern as for total cholesterol following the ingestion of cholesterol-enriched diet and subsequently 


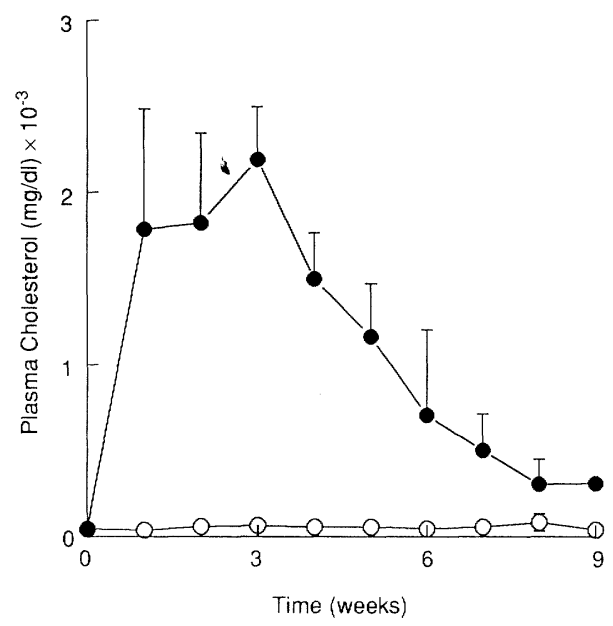

Fig. 1. Total plasma cholesterol levels measured in rabbits fed high-cholesterol (•) and low-cholesterol $(\bigcirc)$ diets. Significance of difference, $p<0.001$.

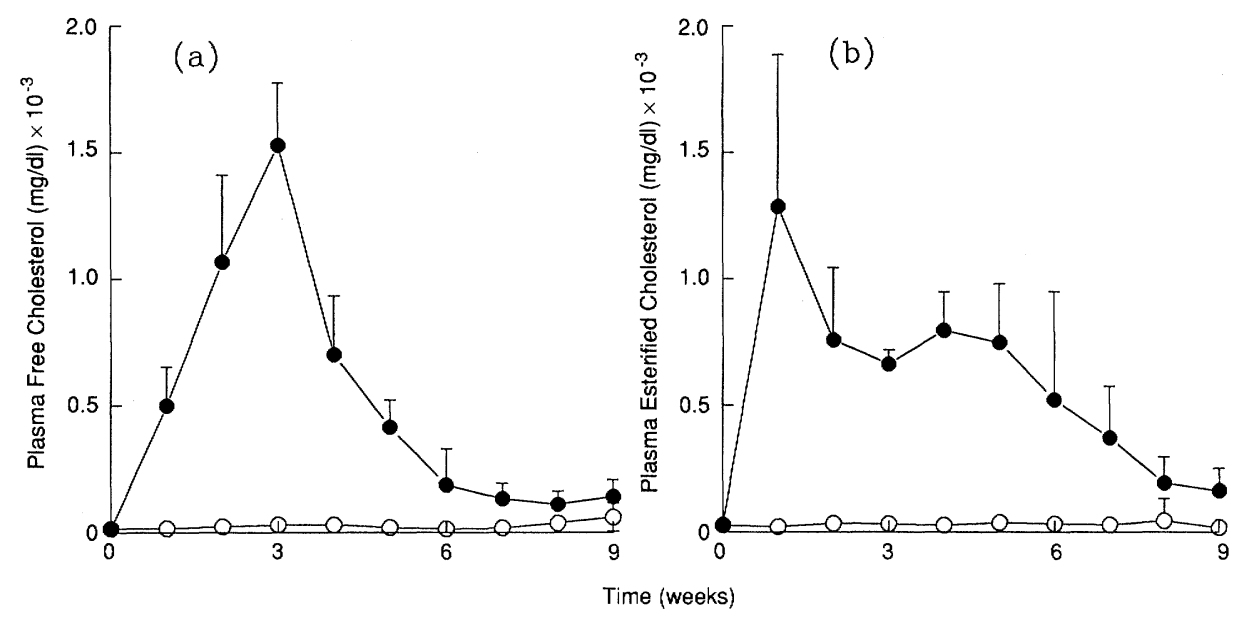

Fig. 2. Plasma free cholesterol (a) and plasma esterified cholesterol (b) measured in rabbits fed high-cholesterol $(\bullet)$ and low-cholesterol $(\bigcirc)$ diets. Significance of difference, $p<$ 0.001 .

the normal diet (Fig. 2(a)). However, the cholesterol ester content of the serum increased only during the first week of the cholesterol-supplemented diet and then decreased linearly over the next 8 weeks (Fig. 2(b)).

\section{Lipid synthesis in monocytes}

The incorporation of $\left[1-{ }^{14} \mathrm{C}\right]$ acetate into monocyte total lipids was significantly lower in animals fed the cholesterol-supplemented diet for 3 weeks (Fig. 3(a)). By 3 weeks into the recovery period, the lipid synthesis by monocytes 


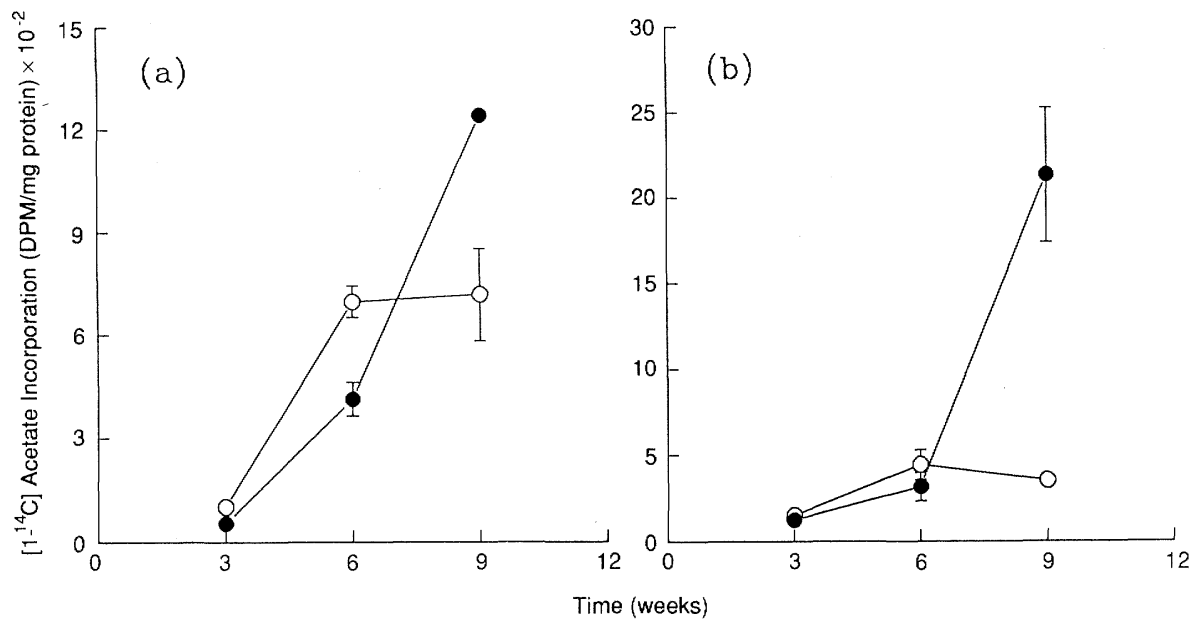

Fig. 3. Incorporation of $\left[1-{ }^{14} \mathrm{C}\right]$ acetate into total lipids by rabbit monocytes isolated at various times from rabbits given the normal, low-cholesterol $(\bigcirc)$ or high-cholesterol $(\bullet)$ diet. The cells were incubated with the radiolabel for $2 \mathrm{~h}$. (a) Monocytes and (b) incubation medium.

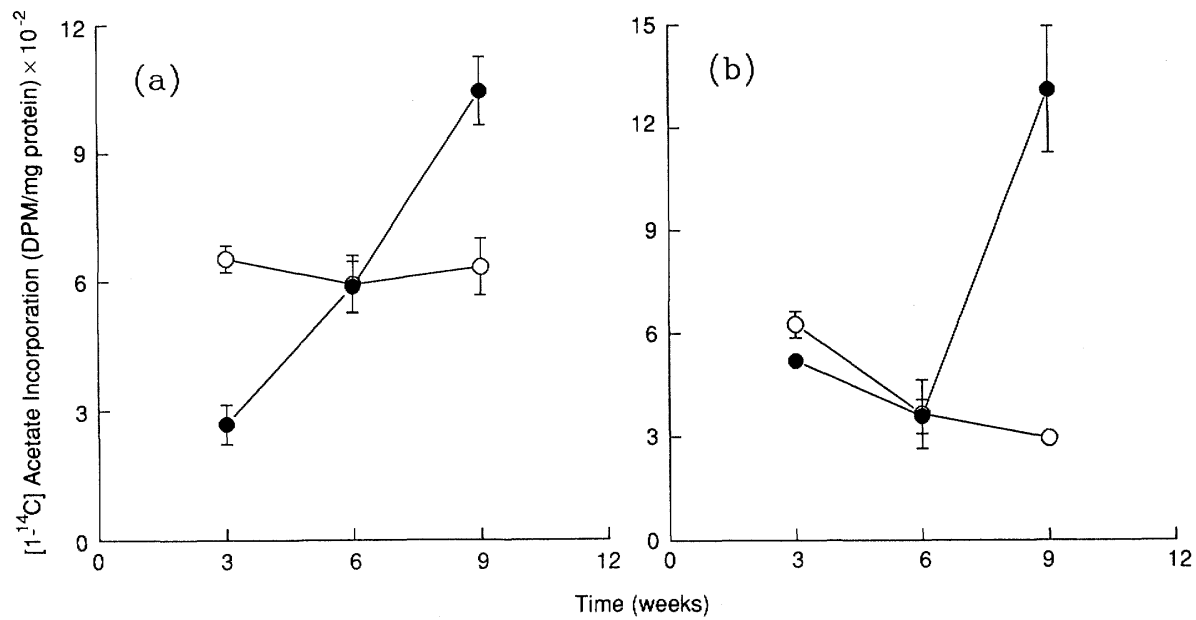

Fig. 4. Incorporation of $\left[1-{ }^{14} \mathrm{C}\right]$ acetate into cholesterol by rabbit monocytes. See legend of Fig. 3 for details.

returned to normal, and at the 9-week period of the dietary regimens, the synthesis of lipids in monocytes was twofold higher than that in cells from animals fed the control diet (Fig. 3(a)). Secretion into the medium of lipids synthesized by the monocytes was not significantly different up to 6 weeks; however, at 9 weeks, the rabbits that had previously been fed the cholesterol-supplemented diet exhibited a higher incorporation of $\left[1-{ }^{14} \mathrm{C}\right]$ acetate into total lipids (Fig. 3(b)). 


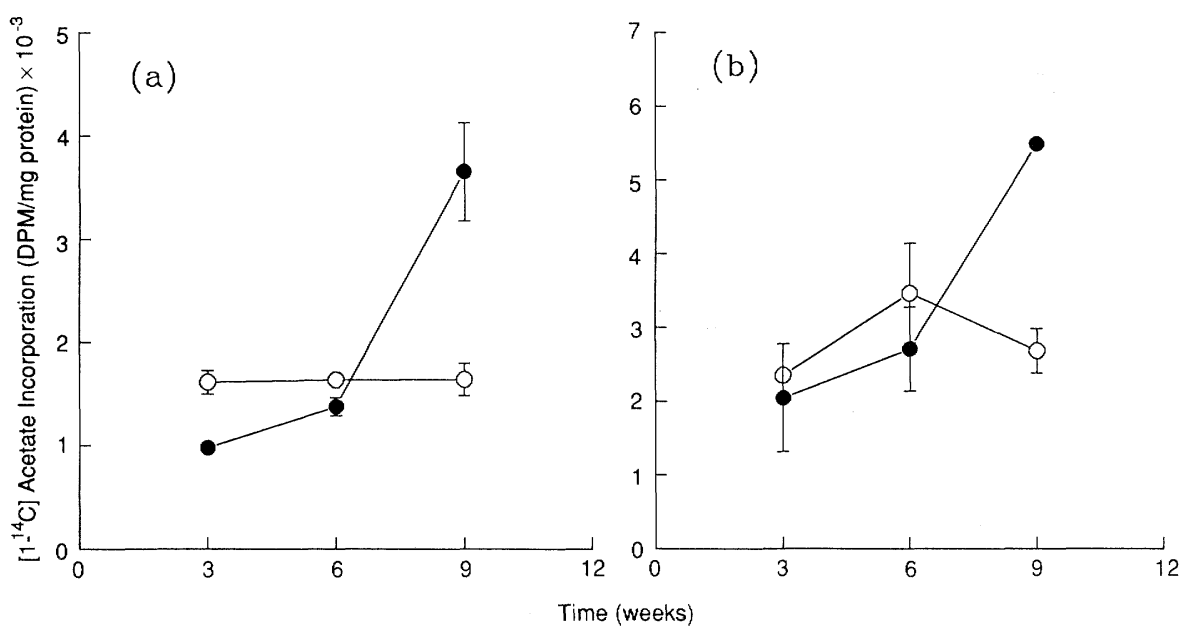

Fig. 5. Incorporation of $\left[1-{ }^{14} \mathrm{C}\right]$ acetate into triacylglycerols by rabbit monocytes. See legend of Fig. 3 for details.
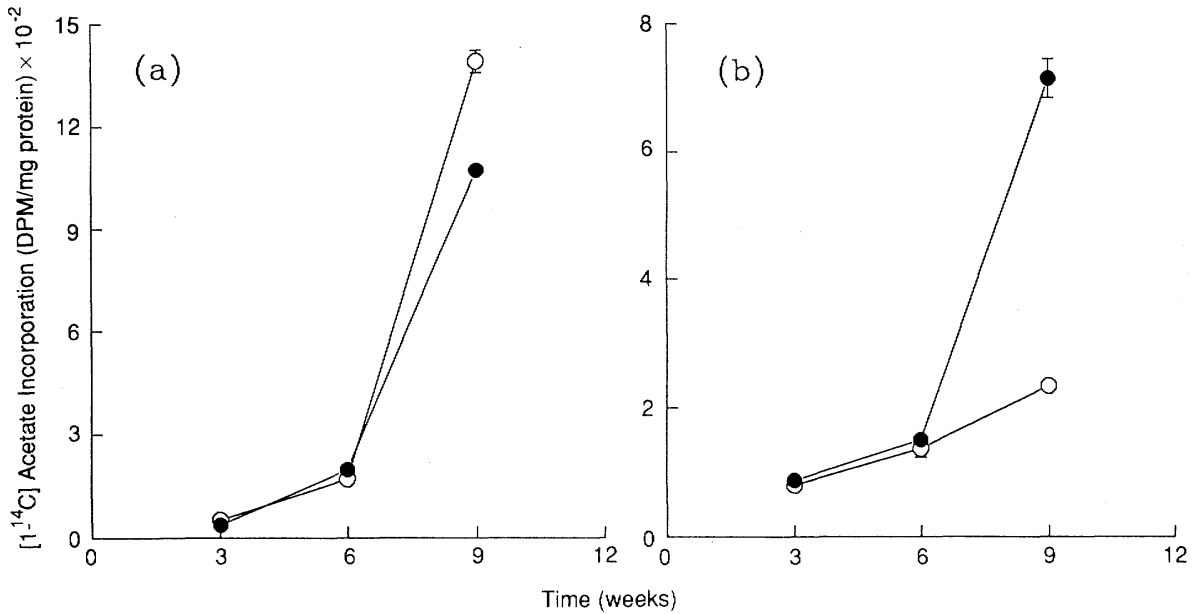

Fig. 6. Incorporation of $\left[1-{ }^{14} \mathrm{C}\right]$ acetate into free fatty acids by rabbit monocytes. See legend of Fig. 3 for details.

The fractionation of total lipids showed that the pattern of $\left[1-{ }^{14} \mathrm{C}\right]$ acetate incorporation into unesterified cholesterol and free fatty acid fraction was similar to that of total lipids in both the cellular and secreted lipids; i.e., an initial inhibition of synthesis of lipids in these fractions was seen while the animals were being fed the cholesterol-enriched diet, and then at nine weeks, when the animals were recovering, the synthesis was significantly higher in the cholesterol-supplemented group (Figs. 4(a) and (b), 5(a) and (b)).

The synthesis of triacylglycerols and cholesterol esters from $\left[1-{ }^{14} \mathrm{C}\right]$ acetate was similar up to 6 weeks of feeding the regimens in both the cellular lipids and 


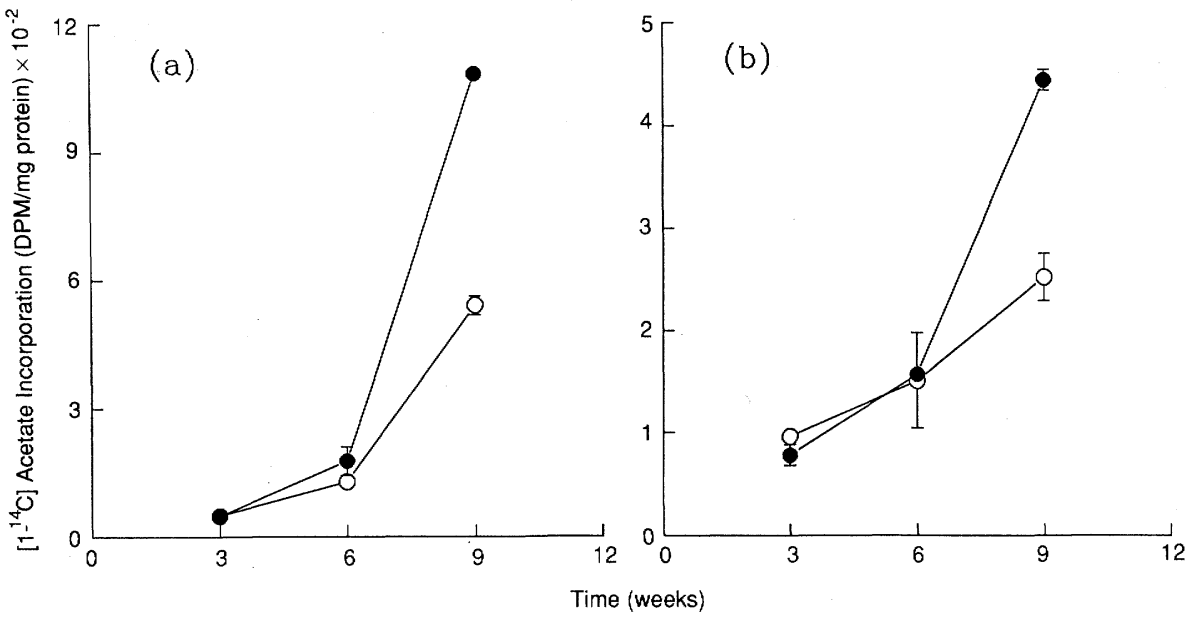

Fig. 7. Incorporation of $\left[1-{ }^{14} \mathrm{C}\right]$ acetate into total phospholipids by rabbit monocytes. See legend of Fig. 3 for details.

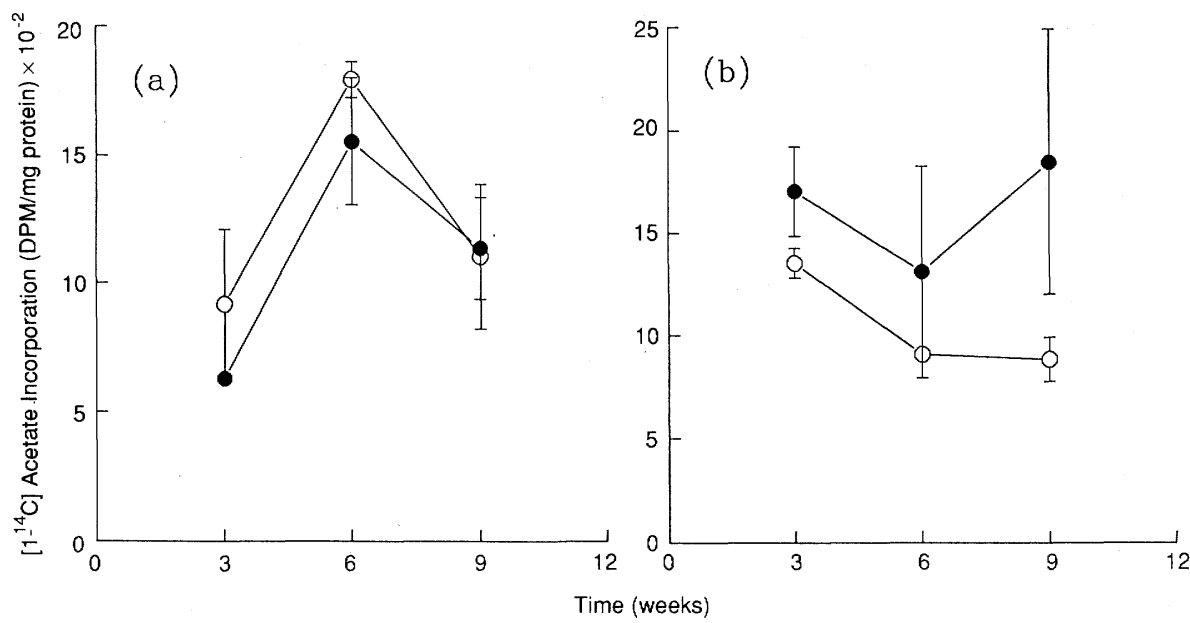

Fig. 8. Incorporation of $\left[1-{ }^{14} \mathrm{C}\right]$ acetate into cholesterol esters by rabbit monocytes. See legend of Fig. 3 for details.

the lipids secreted by the monocytes into the medium (Figs. 6(a) and (b), 7(a) and (b)). At 9 weeks, the synthesis of neutral lipids (both triacylglycerol and cholesterol ester) was sharply increased. In the monocyte lipids, the radioactivity incorporation into the triacylglycerol fraction was lower in rabbits that had previously been fed the cholesterol-supplemented diet (Fig. 6(a)). In secreted lipids, however, these animals had higher synthesis of triacylglycerols (Fig. 6(b)). Similarly, in the cholesterol ester fraction, the cholesterol-supplemented group exhibited higher incorporation of $\left[1-^{14} \mathrm{C}\right]$ acetate into cellular and secreted lipids (Fig. 7(a) and 
(b)). Administration of $2.5 \%$ cholesterol in the diet did not alter phospholipid synthesis from $\left[1-{ }^{14} \mathrm{C}\right]$ acetate in the cellular lipids (Fig. 8(a)); however, in the secreted lipids, the radioactivity incorporation was higher in cholesterol-supplemented group at all time periods examined (Fig. 8(b)).

\section{DISCUSSION}

Blood monocytes are considered to be the major origin of foam cells present in fatty streak lesions of mature atherosclerotic plaques [2]. Monocyte-derived macrophages have been shown to possess a variety of receptors for the uptake of lipoprotein and other substances [18-21]. They are also capable of synthesizing and processing lipids $[19,22,23]$. Under normal circumstances an equilibrium between lipid uptake, synthesis, and secretion is maintained in these cells because homeostatic mechanisms tend to maintain an appropriate lipid level. At some stage of life, this equilibrium is broken by unknown signals and mechanism(s), and there starts a net accumulation of cholesteryl ester-rich lipid droplets in macrophages that transforms them into foam cells. The elucidation of these mechanisms is of utmost importance in order to understand the process of atherosclerosis and for the prevention as well as treatment of overt arterial disease. The results presented in this paper demonstrate that diet-induced hypercholesterolemia may cause an irreversible damage to the lipid homeostasis in monocytes by altering their lipid biosynthetic capacity even after removal of the hypercholesterolemia by shifting the animals to a normal diet.

As expected, cholesterol (total and unesterified) levels in the serum increased sharply during dietary cholesterol supplementation and tended to return back to normal when the animals were subsequently fed the normal, low-cholesterol diet. These results are in agreement with previous reports $[24,25]$. On the other hand, esterified cholesterol content of the serum only increased during the first week of dietary cholesterol loading and then decreased in a linear fashion regardless whether the animals were still eating high-cholesterol diet or in the recovery period. The reason for this decrease in serum cholesterol esters during the second and third weeks of cholesterol feeding is not clear but could be due to the saturation of tissue acylCoA: cholesteryl acyltransferase or plasma lecithin: cholesteryl acyltransferase enzymes responsible for cholesterol esterification [26]. The physiological significance of these changes in serum esterified cholesterol content and their relationship with cholesterol homeostasis merit further examination.

Dietary cholesterol loading for 3 weeks was associated with decreased synthesis of total lipids, free cholesterol, free fatty acids, and cholesterol ester fractions in the monocytes as indicated by low incorporation of $\left[1-{ }^{14} \mathrm{C}\right]$ acetate into monocyte and secreted lipids. The effect of cholesterol enrichment on the inhibition of cholesterol synthesis has been previously reported in hepatocytes and fibroblasts $[27,28]$. This is most likely due to feedback inhibition of the rate- 
limiting enzyme of the cholesterol biosynthetic pathway, i.e., hydroxymethylglutaryl CoA reductase. During the six-week recovery period, the cholesterol synthesis not only returned to, but overshot, the synthesis in monocytes of normal animals. Previous studies from our laboratory and others have shown that the reversal of diet-induced hypercholesterolemia does not bring the aortic cholesterol content back to normal; rather, the cholesterol level in the aorta is further increased [25]. Therefore, the present study provides an explanation for cholesterol accumulation in the aorta when animals are recovering from hypercholesterolemia; i.e., cholesterol feeding for a short period of time ( 3 weeks in the present study) may damage the cholesterol homeostasis in monocytes and perhaps in smooth muscle cells also by deregulation of cholesterol synthesis. In this manner, the arterial accumulation of cholesterol and other fats may continue even after the blood cholesterol level has returned to normal. The fact that dietary cholesterol alters fatty acid synthesis and metabolism in monocytes/macrophages is being examined further in our laboratory.

The synthesis of triacylglycerols from $\left[1-{ }^{14} \mathrm{C}\right]$ acetate in rabbit monocytes was not affected during cholesterol feeding period, but after recovery from hypercholesterolemia the overall triacylglycerol synthesis was sharply increased. It is likely that dietary cholesterol enrichment alters the activity of enzymes involved in triacylglycerol synthesis, as has been previously demonstrated for hepatic tissue and swine monocytes $[29,30]$. The changes in triacylglycerol and phospholipid synthesis are in agreement with the reported changes in rabbit peritoneal macrophages [31].

In summary, it appears that short-term cholesterol feeding inhibits lipid biosynthesis in rabbit monocytes and that when animals are subsequently allowed to recover from hyperlipidemia, the lipid synthetic activity does not return to normal but overshoots to a much greater extent compared with the synthesis in normal animals. Therefore, exposure to dietary cholesterol even for a short period of time may cause persistent changes in lipid synthetic capacity of the monocyte and perhaps in macrophage/smooth muscle cells also. These residual alterations may be an important step for their conversion into foam cells during the process of atherogenesis. It must be pointed out that rabbits are highly sensitive to dietary cholesterol feeding; therefore, further studies using other animal species will be required to determine the general importance of present findings.

This work was supported by grants from the Heart \& Stroke Foundation and Medical Research Council of Canada. Andrea Barone gave excellent technical assistance. Authors are thankful to Gina Jarvis for typing this manuscript so promptly.

\section{REFERENCES}

1. Jayakody, L., Sanaratne, M., Thomson, A., and Kappagoda, T. (1987): Endotheliumdependent relaxation in experimental atherosclerosis in the rabbit. Circ. Res., 60, 251-264.

2. Jayakody, L., Kappagoda, T., Sanaratne, M., and Thomson, A.B.R. (1988): Impairment of 
endothelium-dependent relaxation: An early marker of atherosclerosis in the rabbit. $B r . J$. Pharmacol., 94, 335-346.

3. Subbiah, M.T.R., Sprinkle, J.D., and Yunker, R.L. (1989): Short-term exposure to high dietary cholesterol in early life: Arterial changes and response after normalization of plasma cholesterol. Am. J. Clin. Nutr., 50, 68-72.

4. Schwartz, C.J., and Mitchell, J.R.A. (1962): Cellular infiltration of the human arterial adventitia associated with atheromatous plaques. Circulation, 26, 73-78.

5. Gerrity, R.G. (1981): The role of monocytes in atherogenesis: I. Transition of blood-borne monocytes into foam cells in fatty lesions. Am. J. Pathol, 103, 181-190.

6. Joris, I., Zand, T., Nunnari, J.J., Krolikowski, F.J., and Majno, G. (1983): Studies on the pathogenesis of atherosclerosis: I. Adhesion and emigration of mononuclear cells in the aorta of hypercholesterolemic rats. Am. J. Pathol., 120, 391-401.

7. Fowler, S., Shio, H., and Haley, N.J. (1979): Characterization of lipid-laden aortic cells from cholesterol-fed rabbits: IV. Investigation of macrophage-like properties of aortic cell populations. Lab. Invest., 41, 372-378.

8. Aqel, N.M., Ball, R.Y., Waldmann, H., and Mitchinson, M.J. (1984): Monocytic origin of foam cells in human atherosclerotic plaque. Atherosclerosis, 53, 265-271.

9. Klurfield, D.M. (1985): Identification of foam cells in human atherosclerotic lesions as macrophages using monoclonal antibodies. Arch. Pathol. Lab. Med., 109, 445-449.

10. Zucker-Franklin, D., Grusky, G., and Marcus, A. (1978): Transformation of monocytes into fat cells. Lab. Invest., 38, 620-628.

11. Day, A.J. (1963): Lipid metabolism by macrophages and its relationship to atherosclerosis. Adv. Lipid Res., 5, 185-205.

12. Brown, M.S., and Goldstein, J.L. (1983): Lipoprotein metabolism in macrophages: Implications for cholesterol deposition in atherosclerosis. Annu. Rev. Biochem., 52, 223-261.

13. Trinder, P. (1969): Determination of glucose in blood using glucose oxidase with an alternative oxygen acceptor. Ann. Clin. Biochem., 6, 24-27.

14. Sidel, J., Schlumberger, H., Kose, S., Ziegenhorn, J., and Wahlfeld, A.W. (1981): Improved reagent for enzymatic determination of serum cholesterol. J. Clin. Chem. Clin. Biochem., 19, 838-839.

15. Edelson, P.J., and Cohn, Z.A. (1976): Purification and cultivation of monocytes and macrophages, in Methods for Studying Mononuclear Phagocytes, ed. by Adams, D.O., Edelson, P.J., and Koren, H., Academic Press, New York.

16. Folch, J., Lees, M., and Sloane-Stanley, G.H. (1957): A simple method for the isolation and purification of total lipids from animal tissues. J. Biol. Chem., 226, 497-509.

17. Lowry, O.H., Rosebrough, N.J., Farr, A.L., and Randall, R.J. (1951): Protein measurement with the folin phenol reagent. J. Biol. Chem., 193, 265-275.

18. Fogelman, A.M., Hokom, M.M., Haberland, M.E., Tanaka, R.D., and Edwards, P.A. (1982): Lipoprotein regulation of cholesterol metabolism in macrophages derived from human monocytes. J. Biol. Chem., 257, 14081-14086.

19. Knight, B.L., Patel, D.D., and Soutar, K.K. (1983): The regulation of 3-hydroxy-3methylglutaryl-CoA reductase activity, cholesterol esterification and expression of lowdensity lipoprotein receptors in cultured monocyte-derived macrophages. Biochem. J., 210, 523-532.

20. Van Lenten, B.J., Fugelman, A.M., Hokom, M.M., Benson, L., Haberland, M.E., and Edwards, P.A. (1983): Regulation of the uptake and degradation of $\beta$-very low density lipoprotein in human monocyte macrophages. J. Biol. Chem., 258, 5151-5157.

21. Alam, R., Yatsu, F.M., Tsui, L., and Alam, S. (1989): Receptor mediated uptake and retroendocytosis of high density lipoproteins by cholesterol-loaded human-monocytederived macrophages. Possible role in enhancing reverse cholesterol transport. Biochim. Biophys. Acta, 1004, 292-299.

22. Fogelman, A.M., Seager, J., Edwards, P.A., Hokom, M., and Popjak, G. (1977): Cholesterol biosynthesis in human lymphocytes, monocytes and granulocytes. Biochem. Biophys. Res. 
Commun., 76, 167-173.

23. Bell, F.P., and Schaub, R.G. (1989): Comparison of lipid accumulation and metabolism in carrageenan-induced granulomas to aorta and blood monocyte of normal and cholesterolfed rabbits. Exp. Mol. Pathol., 50, 327-336.

24. Mustani, R., Chiari, A., and Ghiselli, G. (1991): Peritoneal macrophage cholesteryl ester content as a function of plasma cholesterol in rats. Arterioscler. Thromb., 11, 1111-1119.

25. Jayakody, L., Senaratne, M.P.J., Thomson, A.B.R., Sreeharan, N., and Kappagoda, C.T. (1989): Persistent impairment of endothelium-dependent relaxation to acetylcholine and progression of atherosclerosis following 6 weeks of cholesterol feeding in the rabbits. Can. J. Physiol. Pharmacol., 67, 1454-1460.

26. Norum, K.R., Berg, T., Helgerud, P., and Drevon, C.A. (1983): Transport of cholesterol. Physiol. Rev., 63, 1344-1419.

27. Brown, M.S., Danna, S., and Goldstein, J.L. (1973): Regulation of 3-hydroxy-3-methylglutaryl coenzyme A reductase activity in human fibrolbasts by lipoproteins. Proc. Natl. Acad. Sci. U.S.A., 70, 2162-2166.

28. Lakshmanan, M.R., Muesing, R.A., and LaRosa, J.C. (1980): Regulation of cholesterol biosynthesis and 3-hydroxy-3-methylglutaryl coenzyme A reductase activity by chylomicron remnants in isolated hepatocytes and perfused liver. J. Biol. Chem., 256, 3037-3043.

29. Ueno, K., Hayashi, H., Moriuchi, A., and Okuma, H. (1985): Effect of a high cholesterol diet on lipid metabolising enzymes in spontaneously hypertensive rats. Biochim. Biophys. Acta, 837, 173-180.

30. Bell, F.P., and Gerrity, R.G. (1992): Evidence for an altered lipid metabolic state in circulating blood monocytes under conditions of hyperlipemia in swine and the implications in arterial lipid metabolism. Arterioscler. Thromb., 12, 155-162.

31. Kar, S., and Day, A.J. (1977): Composition and metabolism of lipid in macrophages from normally fed and cholesterol fed rabbits. Exp. Mol. Pathol., 28, 65-75. 